\title{
BMJ Open Sexuality post gynaecological cancer treatment: a qualitative study with South African women
}

\author{
Sorrel Pitcher (D) , ${ }^{1}$ Nazia Fakie, ${ }^{1,2}$ Tracey Adams, ${ }^{1,3}$ Lynette Denny, ${ }^{1,3}$ \\ Jennifer Moodley ${ }^{1,4,5}$
}

To cite: Pitcher S, Fakie N, Adams T, et al. Sexuality post gynaecological cancer treatment: a qualitative study with South African women. BMJ Open 2020;10:e038421. doi:10.1136/ bmjopen-2020-038421

- Prepublication history and additional material for this paper is available online. To view these files, please visit the journal online (http://dx.doi.org/10. 1136/bmjopen-2020-038421).

Received 10 March 2020 Revised 04 August 2020 Accepted 07 August 2020

Check for updates

(c) Author(s) (or their employer(s)) 2020. Re-use permitted under CC BY-NC. No commercial re-use. See rights and permissions. Published by BMJ.

${ }^{1}$ UCT/SAMRC Gynaecological Cancer Research Centre, University of Cape Town, Cape Town, Western Cape, South Africa

${ }^{2}$ Radiation Oncology, Groote Schuur Hospital, Cape Town, Western Cape, South Africa ${ }^{3}$ Obstetrics and Gynaecology, Groote Schuur Hospital, Cape Town, Western Cape, South Africa

${ }^{4}$ Cancer Research Initiative, University of Cape Town, Cape Town, Western Cape, South Africa

${ }^{5}$ Women's Health Research Unit, University of Cape Town, Cape Town, Western Cape, South Africa

Correspondence to

Sorrel Pitcher;

sorrel.p@gmail.com

\section{ABSTRACT}

Objectives This study investigated women's experiences of their sexuality post gynaecological cancer treatment. Using a holistic sexuality framework, the study explored how women felt their sexual functioning, sexual relationships and sexual identity had been affected by treatment.

Design The study was qualitative in nature and made use of an interpretive descriptive design. Data were analysed using thematic analysis.

Setting Data collection took place at a follow-up clinic within the gynaeoncology unit at a public-sector tertiary hospital in Cape Town, South Africa.

Participants Purposive sampling was used to recruit participants, and the final sample consisted of 34 women aged 29-70 ( $x=52)$. All women had received a gynaecological cancer diagnosis and had been treated with either surgery, chemotherapy, radiation or a combination of these. On average, the participants were between 12 and 30 months post treatment.

Results Women expressed how their sexual functioning post treatment was both nuanced and complex, how heteronormative gender expectations influenced their intimate relationships, and how they experienced a reembodiment of their sexual subjectivity post treatment. Participants felt that more sexual functioning information from healthcare providers, as well as peer support groups, would assist them in navigating the sexuality changes they experienced.

Conclusions The findings of this study broaden conceptualisations of sexuality post treatment by detailing the ways that it is complex, nuanced, relational and ever shifting. More research is needed about how to incorporate holistic psychosexual support post treatment into the public healthcare system in South Africa.

\section{BACKGROUND}

Sexuality in the context of gynaecological cancer treatment is frequently sidelined in clinical contexts because it does not relate to the eradication of the cancer itself. ${ }^{12}$ In this article, the WHO's 2010 definition of sexuality is used as the underlying understanding of sexuality. ${ }^{3}$ This states that sexuality encompasses sex, gender identities and roles, sexual orientation, eroticism, pleasure, intimacy and reproduction, and is influenced

\section{Strengths and limitations of this study}

The use of a holistic sexuality framework allowed for sexual functioning to be considered beyond physical acts of intercourse.

- The cross-sectional nature of the study means that comments cannot be made about how participants experienced their sexuality post treatment longitudinally.

- The theoretical framework used is not exhaustive and did not include sociocultural factors relating to sexuality.

- The sample of this study comprised predominantly older cisgender women in long-term relationships with men, and therefore this study could not explore the experiences of younger women, women who are not partnered, queer women and non-binary or transgender persons with cervixes and vulvas.

by the interaction of biological, psychological, social, economic, political, cultural, ethical, legal, historical, religious and spiritual factors. Persons living with cancer are often asexualised because they fall outside of conceptualisations of 'normative' sexuality. ${ }^{4}$ Yet, for many individuals, sexual well-being is an important quality of life factor. ${ }^{56}$ Research suggests that $40 \%-100 \%$ of women with gynaecological cancer will experience sexual difficulties post treatment. ${ }^{7-9}$ Common problems include decreased desire; low frequency of sexual activity, sexual pleasure and satisfaction; high levels of discomfort; loss of vaginal elasticity; deep dyspareunia; vaginal dryness and shortening; and difficulty with orgasm. ${ }^{10}$ Side effects that manifest in other areas of the body, such as urinary or bowel dysfunction and fatigue, also hinder sexual activity. These alterations can last for years into survivorship and may become chronic. ${ }^{11}$ Healthcare providers find it difficult and often feel ill-equipped to communicate about sexuality with their patients, ${ }^{12-14}$ which leads to inconsistencies in psychosexual support post treatment. ${ }^{15}$ 
Gaining a comprehensive understanding of women's lived experiences of sexuality post treatment is imperative to patient-centred care and comprehensive support programmes in South Africa.

Cervical cancer is the most common gynaecological cancer in South Africa and the second most common cancer in women after breast cancer, with an agestandardised incidence rate per 100000 of $23 .{ }^{16}$ The agestandardised incidence rates per 100000 for cancer of the uterus, ovary, vulva and vagina are $5,2,1$ and 0.7 , respectively. ${ }^{16}$ Accordingly, most of the research has focused on cervical cancer compared with other gynaecological cancers. Cervical cancer prevention has concentrated on population-based screening in the form of free Papanicolaou smears. ${ }^{17}$ Unfortunately, most women typically self-present to health facilities when symptomatic and in advanced stages, commonly stage IIIB, ${ }^{18}{ }^{19}$ where definitive radiotherapy is the treatment of choice. The higher doses received, compared with adjuvant radiotherapy, may likely result in higher levels of sexual dysfunction. ${ }^{20}$

\section{METHODS}

The main research question was: How do women experience their sexuality post gynaecological cancer treatment? The subquestions were as follows: (1) What are women's experiences of their sexual functioning post treatment? (2) In what ways has this impacted their sexual self-concept? (3) How has this affected their sexual relationships? (4) What are their thoughts on how best their sexual health needs can be addressed as part of cancer care?

\section{Theoretical framework}

This study used the neo-theoretical framework of sexuality, a framework conceptualised by Woods, ${ }^{21}{ }^{22}$ and then expanded on by Cleary and Hegarty ${ }^{23}$ through analysis of empirical literature about sexuality in the context of gynaecological cancer. This framework posits that sexuality in the context of gynaecological cancer comprised three interconnected factors: (1) sexual self-concept, (2) sexual relationships and (3) sexual function. ${ }^{23}$ The framework was chosen for this study in order to move away from solely biomedical understandings of sexuality post gynaecological cancer treatment to more comprehensive conceptualisations which acknowledge the material, intrapsychic and relational aspects of sexuality. ${ }^{24}$ Apart from outlining this study's theoretical understanding of sexuality, this framework also guided the research questions and interview schedule and informed the deductive stage of data coding.

\section{Study design}

This was a qualitative study that used an interpretive descriptive design. Interpretive description aligns philosophically with naturalistic observation and borrows strongly from grounded theory, ethnography and phenomenology.25 26 Interpretive description aims to provide a comprehensive summary of a phenomenon as well as offer explanations of what the themes within the data signify. ${ }^{27}$ It also pays attention to subjective perceptions and acknowledges the contextual and constructed nature of human experiences, ${ }^{28}$ which creates space for exploring multiple perspectives within the data. Interpretive descriptive studies are largely problem-driven and aim to generate knowledge that is clinically applicable. ${ }^{29}$ Such a research design is effective for health sciences research because it creates 'tentative truth claims, ${ }^{26}$ about what is common about people's experiences of a clinical phenomenon. In this way, the research output can provide the background for health-related planning, assessment and interventions. ${ }^{26}$

\section{Sampling and recruitment}

Participants were recruited using purposive sampling, which is a non-random sampling technique whereby participants are chosen because they have experience with a phenomenon of interest and thus can provide rich information on the topic. ${ }^{30}$ Women who had received treatment for gynaecological cancers at a tertiary level, public-sector hospital in Cape Town were recruited from the weekly follow-up clinic that takes place within the radiation oncology unit.

Participants were eligible for the study if they were 18 years or older and had received treatment for cervical, uterine, vulvar or ovarian cancer, or a combination of these, in the past 6-36 months. Participants had to fall into one of the following treatment categories: surgery only, radiation (with or without preceding surgery), or surgery followed by radiation or concurrent chemoradiation. Participants needed to be conversant in either English, Afrikaans, isiXhosa or isiZulu and needed to score 0,1 or 2 on the Eastern Cooperative Oncology Group performance status to be recruited.

Women who met the inclusion criteria were identified through their hospital files by the radiation oncologist (NF) and gynaeoncologist (TA) involved in the follow-up clinic. On completion of their follow-up appointment, eligible women were informed about the study and interested women were referred to the research nurse. The research nurse gave further information about the study, and if potential participants wished to proceed they completed the informed consent procedures. This process was conducted in the participant's home language. In accordance with established qualitative research protocols, recruitment ceased when information redundancy was reached. ${ }^{31}$

\section{Data collection and analysis}

Data collection occurred in two phases: pilot interviews and actual data collection. The pilot interviews were used to test the interview guide, and the data from these interviews were not included in the final analysis. Both sets of interviews were conducted in participants' home language by either the research nurse or the Gynaecological Cancer Research Centre's qualitative researcher 
Table 1 Participant demographics

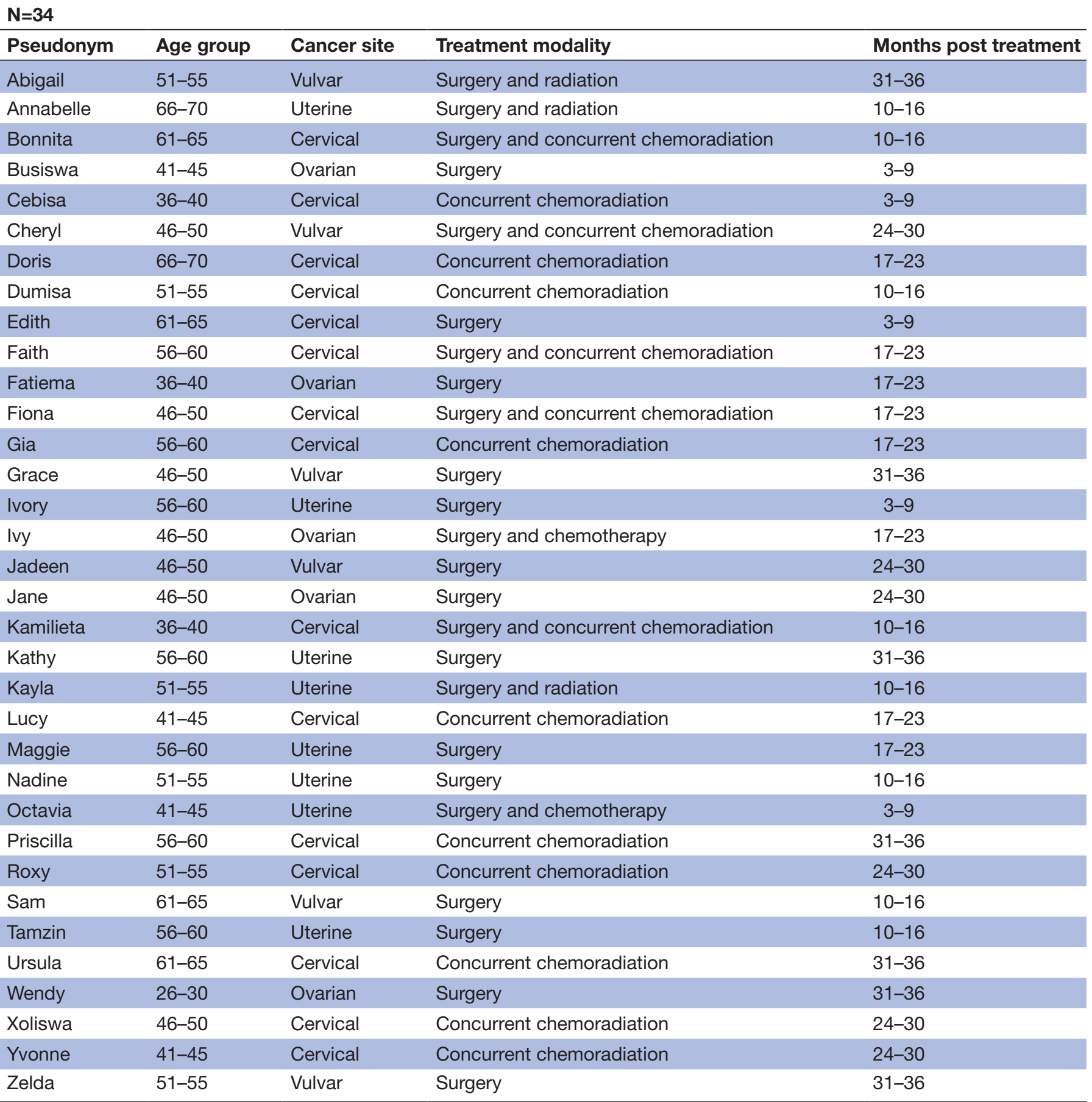

(SP), both of whom are female. Interviews took place in a private space in the radiation oncology unit and lasted between 30 and $90 \mathrm{~min}$. Only the participant and interviewers were present for the interviews. Before beginning the interview, the participants signed a consent form and completed a brief demographic questionnaire asking about age, home language/s, current relationship status, diagnosis, treatment/s and time post treatment. At the beginning of the interview, the participants were asked to choose a pseudonym, which was used to ensure their anonymity throughout the research process, including their transcripts, during analysis and in any published material (see table 1). Partner's and children's names as well as any other identifying information were removed.

The pilot interviews, conducted in May 2018, demonstrated that, despite extensive training of the interviewers with regard to interviewing about sensitive topics, participants struggled to articulate their experiences of sexuality post treatment. This is not unexpected as this study exists at the intersection of two topics which remain highly stigmatised in contemporary South African society: female sexuality and cancer. Given these challenges, the 
interview guide was rearranged to flow more logically, and pile sorting was incorporated to facilitate participants' expression. ${ }^{32-34}$

Pile sorting is a well-established qualitative research methodology and can be used in multiple ways. ${ }^{35}$ It involves presenting a participant with words, objects or images and asking them to sort these into categories that make sense to them. The purpose of this is to identify the ways in which people think about certain concepts and experiences. ${ }^{35}$ A structured pile sort using words was employed, where participants were guided as to how to sort the words. For example, 'Please select all the words that describe how you felt about your body image before your cancer treatment'. Participants were also allowed to include any words of their own that they felt best described their experiences but were not on the cards presented by the interviewer. The pile sorting acted as a catalyst for discussion and formed concrete reference points that could be used throughout the interview. This methodology has been widely used in public health research ${ }^{35-37}$ and has been shown to be effective in gender and sexuality research in low- and middle-income countries. ${ }^{38} 39$

Following the pilot interviews, data were collected through semistructured, face-to-face, indepth interviews in conjunction with pile sorting. Interview questions were based on the central elements of the neo-theoretical framework of sexuality ${ }^{23}$ : (1) sexual self-concept, (2) sexual relationships and (3) sexual function. Participants were asked how they experienced these aspects of their sexual lives before and after treatment. They were also asked about the sexual functioning information they received from healthcare providers during their treatment and what kind of support they think women need post treatment (see online supplemental appendix A for interview guide). Each participant was interviewed once between September 2018 and February 2019. Interviews were audio-recorded with participants' consent, transcribed for meaning and, where necessary, translated. Fieldnotes were written after each interview was completed. The interview excerpts that appear in this paper have been edited only to the extent that a few irrelevant sentences and words have been replaced with ellipses, and excessive use of colloquialisms such as 'like' and 'um' has been removed.

In keeping with the iterative and cyclical nature of qualitative research, the data analysis and writing stages happened simultaneously and informed each other. NVivo V.12 Pro was used to manage the data and facilitate analysis. Data were analysed using the thematic analysis steps outlined by Clarke et al, ${ }^{40}$ which comprises six stages: familiarisation with the data, generating initial codes, searching for themes, reviewing themes, defining and naming themes, and producing the report. The coding process made use of inductive and deductive approaches. Deductive coding was based on the neo-theoretical framework of sexuality. ${ }^{23}$ For the inductive coding, the concepts and categories that emerged from the data were used as codes, rather than being informed by existing theory or preconceptions about gynaecological cancer and sexuality. Transcripts were not given to participants for review.

\section{Patient and public involvement}

First language Afrikaans and isiXhosa speaking members of the public were asked to give feedback on the comprehensibility of the translated interview schedule and pile sorting words. This took place in the form of focus group discussions. Patients were not involved in this research.

\section{RESULTS}

\section{Participant demographics}

In total, 34 participants were recruited (see table 1). The average age was 52, with a range of 29-70. Most of the women were either married or single; however, although some women classified themselves as 'single', they still had a consistent sexual partner. Afrikaans and English were the most common languages spoken by participants. Cervical cancer was the most common cancer, which is in accordance with national prevalence rates, and most of the women had been treated with surgery. The average time post treatment was 20.3 months, with most women being within 12 and 30 months post treatment.

\section{Overview of results}

Four main themes emerged from the interview data: complexity and nuance in sexual functioning experiences; the influence of heteronormative gender role expectations on sexuality; re-embodiment of the sexual self; and psychosexual support during the cancer journey (see table 2). The complexity and nuance in sexual functioning theme comprised the following subthemes: material changes in sexual functioning; impact of prediagnosis symptoms; intimate partnership dynamics; and the coexistence of pleasure and discomfort. The heteronormative gender role expectations theme includes the following subthemes: 'failing' at femininity and sexual violence. Psychosexual support during the cancer journey consists of the following subthemes: information received from healthcare providers and the need for comprehensive support. These findings contribute to expanding understandings of sexuality within the context of gynaecological cancer as well as trouble existing dominant narratives regarding sexuality post treatment.

\section{Complexity and nuance in sexual functioning experiences}

This theme confirms existing literature relating to material changes in sexual functioning post treatment as well as foregrounding how sexuality in the context of gynaecological cancer involves a diverse array of experiences and feelings that are nuanced, complex, fluctuating and contingent on the relational context. In particular, these results show that symptoms prior to diagnosis also have a detrimental impact on women's sexuality; that women's partners' health and sexual functioning also need to be considered as a factor in sexuality post treatment; and lastly that most participants reported experiencing 


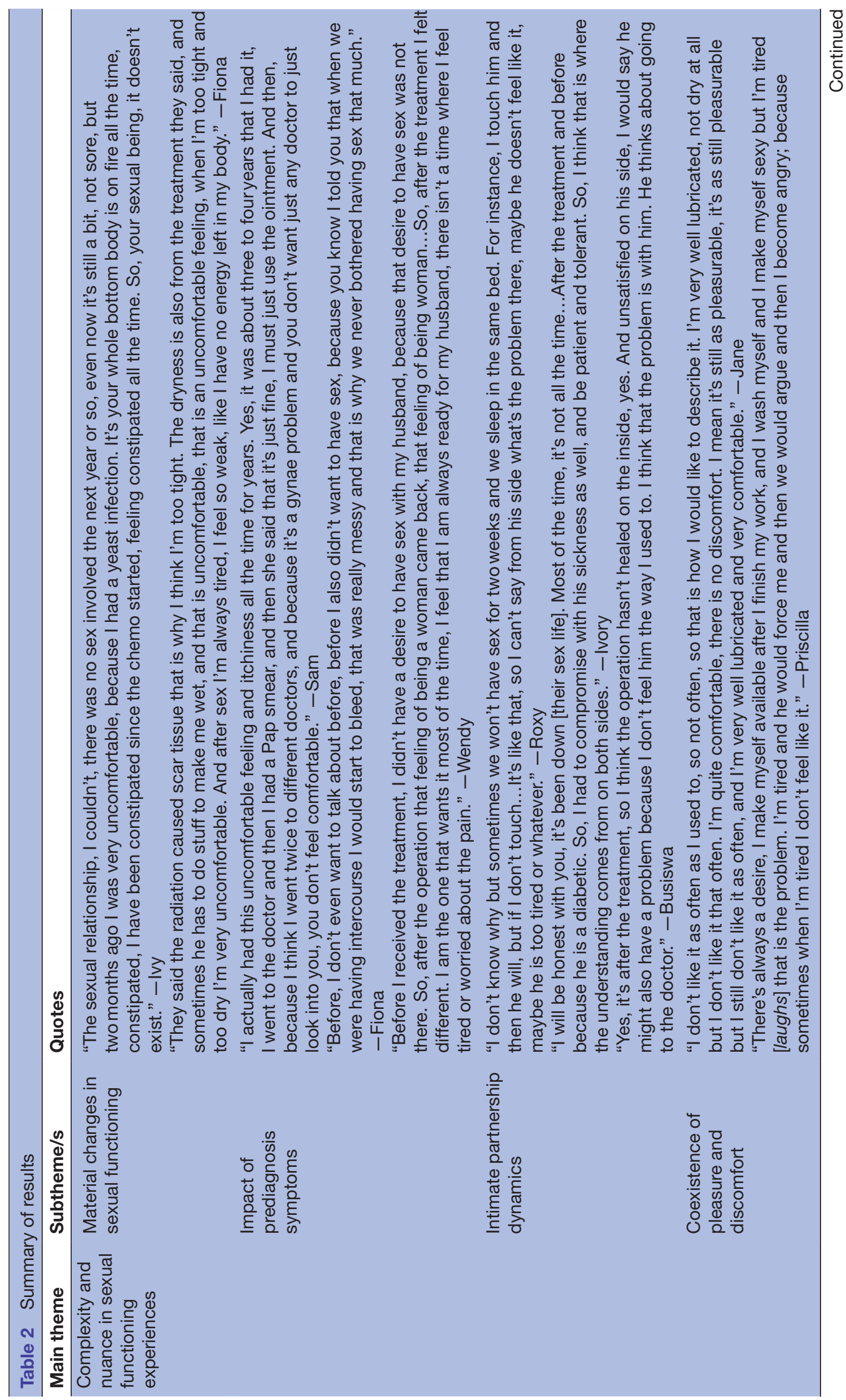




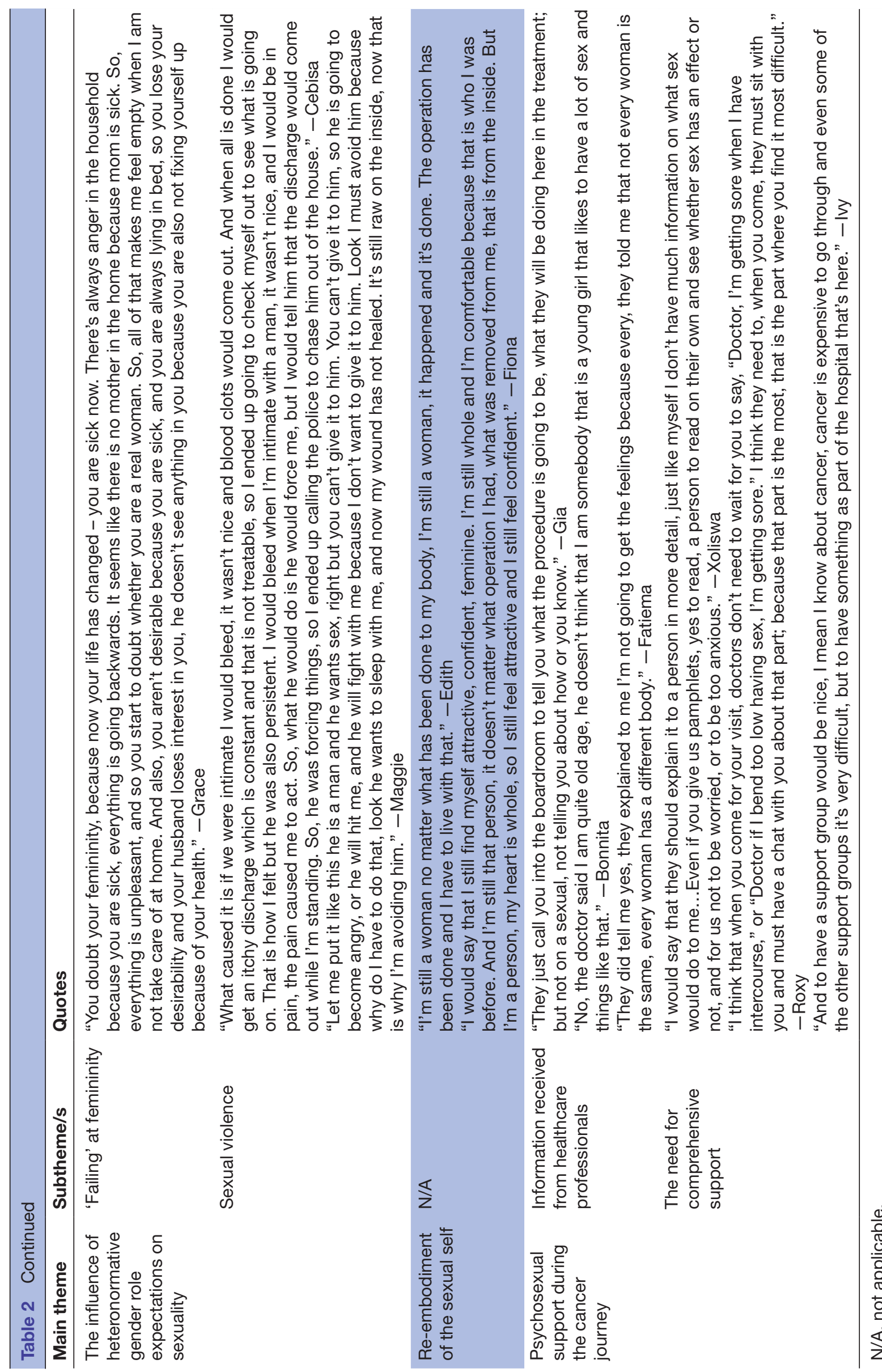


difficulties in one area of their sexual lives while simultaneously experiencing pleasure and fulfilment in other areas.

\section{Material changes in sexual functioning}

Just over half of the participants mentioned sexual difficulties as a result of fatigue post treatment and just under half of the participants struggled with a lack of desire post treatment that was not present beforehand. In addition to this, ongoing pain and dryness were common complaints for approximately a third of participants. Some participants reported significant tightness of the vagina and that it took them longer to lubricate post treatment. Discomfort such as numbness, itching or burning also bothered a few participants, along with some forms of gastrointestinal distress such as constipation, nausea or vomiting.

\section{The impact of prediagnosis symptoms}

Women in this study reported that their symptoms prediagnosis negatively affected their sexual functioning. As shown in Sam and Fiona's quotes (see table 2), living with symptoms such as itchiness and heavy bleeding for an extended period creates disturbances in sexual functioning even before treatment has been received. Sam highlights how her discomfort with having to talk with various doctors about gynaecological problems impeded her from seeking further help even though her symptoms persisted. These excerpts align with what is known in the literature regarding late presentation for diagnosis of gynaecological cancers in South Africa. ${ }^{19}$ For these participants, it took time before a cancer diagnosis was made, and further research on factors that delay timely diagnosis is required. However, some women in this study (eg, Wendy) reported experiencing an improvement in their sexual functioning post treatment because they were no longer burdened with unpleasant symptoms. This highlights the possibility for a diverse range of sexual functioning outcomes post treatment.

\section{Intimate partnership dynamics}

The results of this study also highlight how partnership level factors, such as partners' health issues and sexual functioning difficulties, can influence women's sexual experiences post treatment. Roxy, Ivory and Busiswa's quotes emphasise how a woman's partner is a vital factor to consider in sexual rehabilitation and renegotiation post treatment. For, as Roxy and Ivory explain, partners' sexual functioning difficulties, such as lack of desire and diabetic erectile dysfunction, can impede sexual intimacy. Busiswa acknowledges that she is still healing from her surgery but contemplates whether her husband might also be experiencing a change in sexual functioning-"he might also have a problem"-and thus it is not only her sexuality that is problematised.

\section{The coexistence of pleasure and discomfort}

Participants reported experiencing pleasure and fulfilment in one part of their sexual lives while also experiencing difficulties in others. These results further emphasise that women's sexuality post treatment should not be considered homogeneous nor wholly ruined. Both Jane and Priscilla articulate varied experiences of their sexuality post treatment. Jane describes how, even though her level of desire has decreased, she still finds sex pleasurable when she does have it and that she is free of discomfort and able to lubricate naturally. Priscilla explains how, even though she usually has a desire for sex, her fatigue makes it difficult for her to be intimate with her partner and that this leads to tension and coercion in their relationship. Other women in the study had similar stories of diverse experiences of their sexuality post treatment and not only in relation to physical intercourse. For example, some women described major changes in their physical sexual functioning yet the continuation of other forms of intimacy with their partners. Likewise, some women spoke of feeling differently about their bodies but not having major changes in their ability to have intercourse.

The influence of heteronormative gender role expectations on sexuality

Sexuality cannot be understood outside of gender, for 'sexuality and gender go hand in hand; both are creatures of culture and society, and both play a central and crucial role in maintaining power relations in our societies...Hence, gender provides the critical analytical lens through which any data on sexuality must logically be interpreted...' (p1). ${ }^{41}$ Thus, within this theme, the material effects of cancer treatments on sexuality are acknowledged, while also highlighting how discursive constructions of gender provide the context within which individuals experience their sexual relationships post treatment. ${ }^{42}$

The main trope that participants drew on to describe their relationships post treatment was that of heteronormativity, which is the assumption that heterosexuality is the 'normal' and default sexual orientation and that gender roles and gender differences are immutable and innate. ${ }^{43} \mathrm{~A}$ heteronormative view thus involves alignment of biological sex, sexuality, gender identity and gender roles. In this study, participants narrated a sense of femininity failure post treatment because they were no longer able to fulfil the gender roles expected of them as women. Participants also described how heteronormative expectations of masculinity made sexual violence from their male partners permissible before and after treatment.

\section{'Failing' at femininity}

Within the heteronormative gender system women are expected to fulfil certain roles, which are deemed inherent to womanhood, within society and within their relationships. These may include having children, looking attractive, taking care of their husband and child(ren), being responsible for domestic tasks, having a uterus, having an intact and functional vulva and vagina, having intercourse with their male partner, and always desiring this. Hence, if a woman is unable to fulfil these gender role expectations, her femininity is questioned by herself 
and others. Grace's quote encapsulates the variety of ways in which women in the study felt that they were 'failing' at being a woman post treatment.

Grace experiences the period post treatment as a disruption to her enactment of femininity because she feels she cannot fulfil the expected roles of a mother, a wife and a sexual partner. Her inability to perform these socially prescribed tasks leads her to question her feminine identity. Although these roles are socially constructed, Grace has internalised them, which leads her to be the first to question her feminine subjectivity; however, she explains that her husband is having similar doubts because "he doesn't see anything in [me]." Other participants also experienced both internal and external shaming of their changed womanhood. For example, Wendy stated how, before her treatment, when she was experiencing severe symptoms "Sometimes I would see myself as not good enough as a woman because I used to doubt myself by not being able to satisfy my husband." However, after treatment, she was once again able to fulfil the role of 'good sexual partner', according to her and her husband, because "He sees me as a good woman, as sexy and as a person that he is willing to sleep with." However, other women only experienced shaming from their male partners. This theme highlights how experiences surrounding gynaecological cancer are embedded within broader unequal gendered systems which have the potential to exacerbate an already trying period in women's lives. Hence we see how, in this theme, broader societal ideas around femininity become internalised and used as a standard against which women post treatment (and their partners) evaluate their gender and sexuality.

\section{Sexual violence}

Heteronormative gender role expectations also create space for sexual violence to take place within the context of gynaecological cancer. Participants experienced various forms of sexual violence, such as coercion; forced sex through threats of violence, aggression and infidelity; and rape. As is evident in the quotes by Cebisa and Maggie, many of the women felt that their inability to have sex with their partners due to cancer symptoms or healing post treatment was the trigger for violence. This stems from the idea within the heterosexual script that women are expected to give sex to male partners, which if 'denied' is punishable with violence. Also underlying this violence is the male sexual drive discourse,${ }^{44}$ which is the idea that men need sex all the time, whereas women generally are not interested in sex: "men are not like us, we can go months even years without it but men want to do it all the time." The internalisation of this discourse resulted in some participants putting pressure on themselves to have sex even when they did not feel ready.

\section{Sexual self-concept: re-embodiment post treatment}

The concept of embodiment maintains that the human body and its 'visceral, felt, enlivened bodily experiences ${ }^{45}$ are a worthwhile object of study. Results from the present study show that most of the participants also partook in a process of re-embodiment post treatment. Participants took up a re-embodied sexual subjectivity by emphasising feelings of feminine identity, confidence, strength and attractiveness that exist despite changes to the physical body as a result of treatment. For example, Edith states that she is still a woman regardless of her operation, and Fiona says that she is still "attractive, confident, feminine."

\section{Psychosexual support during the cancer journey}

The last part of the interview asked participants about the information they had received from healthcare providers about sexual functioning, as well as what kinds of support would have been most beneficial to them throughout their cancer journey. The results show that participants had mixed experiences with regard to the information they received and that most participants would like to receive more information from their healthcare providers as well as be able to participate in a support group.

\section{Information received from healthcare providers}

Participants reported a variety of experiences regarding the sexual functioning information they received. Some participants, such as Gia, stated that they did not receive any information; however, most participants did receive information from a healthcare provider about their sexual functioning post treatment, but the results show that this information varied greatly in quality. For example, it appears that some doctors made assumptions about participants' sexual activity based on their age and relationship, as can be seen in the quote from Bonnita. Other participants were told that their sex lives would never be the same again and that this is something they would just have to accept. Other participants, like Fatiema, were given information that was overly generalised and not based on the individual participants' needs and side effects. This emphasises the dire need for healthcare providers working in gynaeoncology to receive further training about discussing sexuality with patients.

\section{The need for comprehensive support}

At the end of each interview participants were asked what kind of support would have been most beneficial to them post treatment. The majority mentioned that they would have liked more detailed sexual well-being information from their healthcare providers. Participants also highlighted that this information could be delivered in a variety of ways, such as in person as well as with informational pamphlets. As is foregrounded in Roxy's quote, participants also want healthcare providers to be the first to broach the topic of sexual functioning. The second most common response was having a support group for gynaecological cancer survivors, and some participants mentioned more empathy from partners and going for individual counselling. 


\section{DISCUSSION}

Sexuality within the context of gynaecological cancer has predominantly been thought of in limiting ways; however, the findings of this study broaden conceptualisations of sexuality post treatment and trouble dominant tropes of oncosexological research. The results of this study support previous literature which calls for a focus on the material, intrapsychic and discursive aspects of sexuality post gynaecological cancer. ${ }^{24}$ It also expands this understanding of sexuality post gynaecological cancer by detailing the ways that it is complex, nuanced, relational and ever shifting.

Most women in this study experienced a change in their sexual functioning post treatment, but half of the participants also reported a significant disruption to their sexual lives prior to treatment due to severe symptoms. Women with late-stage gynaecological cancers often live with symptoms such as abdominal pain, heavy bleeding, unpleasant discharge and fatigue ${ }^{4647}$ for an extended period and therefore their sexuality has been negatively impacted beyond the treatment and post treatment phases. ${ }^{24}$ Limited literature is available on how gynaecological cancer symptoms disrupt sexual functioning before diagnosis and treatment. A few older studies have shown how these symptoms lead to negative changes in all aspects of women's sexual lives. ${ }^{10}{ }^{48-51}$ However, it has been argued that treatment for gynaecological cancer has a greater negative effect on women's sexual functioning than the symptoms of the disease. ${ }^{48}$ The results from the present study challenge this argument by highlighting that, for some women in South African, the symptoms prior to diagnosis are worse-or at least on par-with treatment side effects.

Other important findings were that not all women experienced a negative sexuality change post treatment, and many reported both pleasurable and difficult sexual experiences. Additionally, many women described a process of re-embodiment post treatment where they came to accept and celebrate their sexual identity. Williams' theory of embodiment and chronic illness ${ }^{52}$ suggests that the presence of illness disrupts 'normal' embodiment, and therefore persons make attempts at 're-embodiment' (p32) to make sense of the bodily changes brought about by chronic conditions. When investigating sexual subjectivities post cancer, Gilbert et $a \tilde{l}^{\tilde{3}}$ found that some individuals took up a position of re-embodied sexual subjectivity that comprised acceptance, confidence and engaging in non-coital sexual activity. The dominant narrative around female sexuality post gynaecological cancer treatment in most research and clinical contexts is one of tragedy. The results of the present study trouble catastrophising narratives of sexual identity post treatment and create options for accessing sources of strength and resilience in the recovery process. Feelings of re-embodiment can also be used as a starting point for many women post gynaecological cancer treatment who want to reacquaint themselves with their postcancer body as part of a journey towards resuming their sexual lives.
Some women in this study explained how their partner's sexual (dys)function was a factor in their sexual rehabilitation. Partners are generally overlooked in research on sexuality after cancer, ${ }^{54}$ but existing literature has shown that partners experience a decline in their own libido; fear initiating sex; struggle with regaining a 'normal' sex life; and feel unattractive and unwanted because of sex cessation. ${ }^{55-57}$ Limited research is available on how partners' sexual difficulties are a factor in sexuality post gynaecological cancer; however, Greimel et $a b^{58}$ found that $12 \%$ of their participants were not able to have sexual intercourse post treatment because of their partners' health problems. An interview-based study with male partners of gynaecological cancer survivors ${ }^{59}$ found that male partners also experienced sexual problems after treatment. As an explanation for this, Van De Wiel et $a l^{60}$ suggest that the cancer diagnosis and its treatment are also a crisis for the male partner, which may lead to methods of coping which are signified by withdrawal and can lead to sexual functioning difficulties. However, it is worth noting that Ivory felt her partner's sexual difficulties due to diabetes had made him more empathetic about her sexual difficulties post treatment. Thus, partner comorbidity can be positioned as a catalyst for compassion, bonding and deeper intimacy.

Other participants mentioned how the state of the relationship before treatment either facilitated or hindered sexual intimacy post treatment. For example, pre-existing alcoholism, possessiveness, infidelity and verbal aggression made intimacy post treatment strained. Women who reported that they were generally happy in their relationships and felt supported pretreatment stated that they and their partners were still "going strong" post treatment. Maree $e t a l^{61}$ found similar results in their qualitative study with South African women about partner support through their cervical cancer journey, in that the support experienced post treatment depended on the nature of the relationship prior to treatment. These findings highlight how cancer diagnosis, treatment and rehabilitation are a shared experience for women and their intimate partners, ${ }^{55}$ and thus discussions around sexuality post treatment should focus on the implications for partnerships and not only the individual receiving the treatment. There is debate within the literature about which treatment modality has the greatest negative impact on sexual functioning, ${ }^{23}$ 62-65 with some studies suggesting that radiotherapy leads to higher levels of sexual dysfunction than surgery or chemotherapy. ${ }^{206-69}$ Yet what this finding suggests is that sexuality post treatment is dependent on more than which treatment modality was used. Considering how intimate relationships have been affected by the cancer treatment allows for movement beyond problematising women's sexuality alone.

This study showed how heteronormative gender role expectations negatively impacted women's recovery post treatment and created space for male partners to be sexually violent. Research from the Global North has explored the ways in which heterosexual scripts interact with the 
psychosexual recovery process post treatment. ${ }^{42}$ 70-73 Findings from these studies highlight how the 'coital imperative ${ }^{74}$ impacts couples' ability to renegotiate sexual intimacy. The coital imperative constructs penetrative vaginal sex as the only 'real sex' and as a sign of 'normal', healthy relationships, and therefore those who fall outside of this discursive category are positioned as abnormal and dysfunctional. ${ }^{75}$ It follows then that women who cannot engage in intercourse post treatment begin to doubt their gender and sexual identity.

The same heterosexual scripts that emphasise the 'coital imperative' also make sexual violence post treatment possible. Research on sexual violence within the context of gynaecological cancer care is extremely limited. A few studies regarding the relationship between intimate partner violence (IPV) and cancer exist; however, their focus is largely about whether IPV creates greater risk for cancer among women. ${ }^{77-79}$ The focus of this research is about abuse in general, not sexual abuse, and most of the focus is on cervical cancer. Little attention is paid to whether gynaecological cancer can trigger the perpetration of sexual violence or how it might worsen existing sexual abuse. This issue demands further investigation in South Africa given the country's high levels of sexual violence and cervical cancer. ${ }^{1680}$

Participants in this study stated that they wanted to receive support in the form of more sexual functioning information from their healthcare providers, as well as from support groups. Previous research affirms that people with cancer want healthcare providers to discuss sexuality issues such as when to resume sexual activity, ${ }^{81}$ appropriate sexual positioning or the use of sexual aids, ${ }^{82}$ and adjusting to sexual changes. ${ }^{73}$ Healthcare providers can also give psychoeducation about the effects of gynaecological cancer and its treatments on sexuality throughout the cancer journey, ${ }^{83}$ as well as help couples renegotiate their sexual intimacy by challenging heteronormative discourses of sexuality which stress the coital imperative. $^{42718485}$ In this way, healthcare providers can play a vital role in patients' psychosexual recovery. For, if a healthcare provider legitimises sexuality discussions within a clinical setting, it gives permission to individuals and couples to discuss this on their own. ${ }^{86}$ This can create opportunities for conversations about sexual issues and potentially mitigate relationship tension and sexual violence. ${ }^{4287}$ Healthcare providers working with patients with gynaecological cancer should endeavour to improve their knowledge about sexuality in the context of cancer by staying up to date with the relevant literature as well as attending workshops and conferences. Additionally, healthcare providers should be the first to broach the topic with their patients as patients want to receive more information about sexuality but often feel uncomfortable asking questions.

Other types of interventions that have been aimed at sexual functioning post gynaecological cancer include psychoeducational interventions, ${ }^{88-90}$ peer support interventions, ${ }^{91} 92$ vaginal dilators after pelvic radiotherapy, ${ }^{93} 94$ specialist nurse-led interventions, ${ }^{90}{ }^{95-98}$ reflection-based interventions $^{99}$ and internet-based interventions. ${ }^{100}$ Systematic reviews show that solely information-based interventions do not provide long-term benefits to women with gynaecological cancer, but that counsellingbased interventions are useful in improving quality of life factors. ${ }^{101102}$ Other reviews have shown that interventions are most effective when they include information provision, cognitive-behavioural therapy, social support and counselling $^{88}$ and are led by specialist nurses. ${ }^{88} 96$ There is currently no research on such interventions within the South African public healthcare context. Thus, future research should focus on ascertaining what, if any, interventions exist in South Africa and, if not, what resources are available to create comprehensive support interventions post treatment and how these might fit into the existing healthcare system.

\section{CONCLUSION}

Research and clinical work need to make room for the complexities highlighted in these findings so that sexuality post treatment can be engaged with beyond biomedical assessments of (dys)function, performance and satisfaction. This research has expanded understandings of sexuality within the context of gynaecological cancer and problematised some taken-for-granted assumptions about sexuality post treatment. Researchers should explore how comprehensive sexuality education and sensitivity training can be better incorporated into healthcare providers' training curriculums. Further research is required to understand how partners of women with gynaecological cancer experience and cope with the sexual changes post treatment, how the couple as a partnership negotiates changes post treatment, and the facilitators and barriers that healthcare providers experience regarding discussing sexuality issues with patients.

This study had several limitations. The study was crosssectional in nature and therefore only captured women's experiences of their sexuality at one moment in time post treatment and comments therefore cannot be made on how they experienced their sexuality over time. This study made use of a holistic framework of sexuality; however, this framework is not exhaustive and did not include sociocultural factors relating to sexuality. Given South Africa's diverse sociocultural landscape, such an avenue of exploration would have been beneficial. The authors would also recommend adding a sociocultural component to the holistic framework. The sample of this study predominantly comprised older cisgender women in long-term relationships with men, and therefore this study could not explore the experiences of younger women, women who are not partnered, queer women and non-binary or transgender persons with cervixes and vulvas. Lastly, insufficient attention was paid to the ways in 
which the different components of sexuality post gynaecological cancer treatment interact with each other.

It is hoped that this research will further scholarly and clinical work within this field in South Africa because all gynaecological cancer survivors and their partners should have the resources to create a sexual life that is pleasurable, consensual and fulfilling.

Acknowledgements This paper is dedicated to Dr Leon van Wijk, a devoted colleague who passed away before the publication of this study. Dr van Wijk worked tirelessly as part of the Gynaecological Cancer Research Centre's (GCRC) Qualitative Research Committee and was integral in starting this study. He cared greatly about the comprehensive well-being of his patients and his legacy lives on in this work. The authors would also like to thank Sr Patricia Mtiya for her hard work and dedication during data collection; Thabisa Maphiri for her exceptional transcription and translation; and Jodi Le Roux for her wonderful editing.

Contributors SP was the project leader and JM was the senior author. NF and TA were responsible for recruitment of participants. SP was responsible for data collection and analysis. JM, LD and SP drafted the manuscript. All authors gave critical comment throughout the writing process. All authors were responsible for the conceptualisation and design of the project. All authors approved the final version to be published.

Funding This work was supported by the GCRC, which is funded by the South African Medical Research Council (SAMRC) (grant number: MRC-RFC-CCRC-01-2014).

Competing interests None declared.

Patient consent for publication Not required.

Ethics approval The research was approved by the University of Cape Town's Health Research Ethics Committee (HREC REF: 716/2017) and given hospital institutional approval.

Provenance and peer review Not commissioned; externally peer reviewed.

Data availability statement Raw data from this study are currently not publicly available but can be made available upon reasonable request.

Open access This is an open access article distributed in accordance with the Creative Commons Attribution Non Commercial (CC BY-NC 4.0) license, which permits others to distribute, remix, adapt, build upon this work non-commercially, and license their derivative works on different terms, provided the original work is properly cited, appropriate credit is given, any changes made indicated, and the use is non-commercial. See: http://creativecommons.org/licenses/by-nc/4.0/.

ORCID iD

Sorrel Pitcher http://orcid.org/0000-0003-2059-5892

\section{REFERENCES}

1 Hordern A. Intimacy and sexuality after cancer: a critical review of the literature. Cancer Nurs 2008;31:E9-17.

2 Hughes MK. Sexuality and cancer: the final frontier for nurses. Oncol Nurs Forum 2009;36:E241-6.

3 WHO/RHR/HRP/10.22. A framework for action. In: Developing sexual health programmes. Geneva: World Health Organization, 2010. http://whqlibdoc.who.int/hq/2010/WHO_RHR_HRP_10.22_ eng.pdf

4 Shildrick M. Unreformed bodies: normative anxiety and the denial of Pleasure. Womens Stud 2005;34:327-44.

5 Reis N, Beji NK, Coskun A. Quality of life and sexual functioning in gynecological cancer patients: results from quantitative and qualitative data. Eur J Oncol Nurs 2010;14:137-46.

6 World Health Organisation. The world health organisation quality of life assessment (WHOQOL) position paper from the world health organisation. Soc Sci Med 1995;41:1409.

7 Audette C, Waterman J. The sexual health of women after gynecologic malignancy. J Midwifery Womens Health 2010;55:357-62.

8 Wiggins DL, Wood R, Granai CO, et al. Sex, intimacy, and the gynecologic oncologists: survey results of the new England association of gynecologic oncologists (NEAGO). J Psychosoc Oncol 2007;25:61-70.
9 Guner O, Gumussoy S, Çelik N, et al. An examination of the sexual functions of patients who underwent a gynecologic cancer operation and received brachytherapy. Pak J Med Sci 2018;34:15.

10 Bourgeois-Law G, Lotocki R. Sexuality and gynaecological cancer: a needs assessment. Can J Human Sexual 1999;8:231.

11 Tierney DK, Tierney DK. Sexuality: a quality-of-life issue for cancer survivors. Semin Oncol Nurs 2008:24:71-9.

12 Ratner ES, Foran KA, Schwartz PE, et al. Sexuality and intimacy after gynecological cancer. Maturitas 2010;66:23-6.

13 Reese JB, Bober SL, Daly MB. Talking about women's sexual health after cancer: why is it so hard to move the needle? Cancer 2017;123:4757-63.

14 Reese JB, Sorice K, Beach MC, et al. Patient-provider communication about sexual concerns in cancer: a systematic review. J Cancer Surviv 2017;11:175-88.

15 Flynn KE, Reese JB, Jeffery DD, et al. Patient experiences with communication about sex during and after treatment for cancer. Psychooncology 2012;21:594-601.

16 National Cancer Registry. Cancer in South Africa, 2014: full report. South Africa: National Health Laboratory Service, 2014.

17 South African National Department of Health. Cervical cancer prevention and control policy, 2017.

18 Snyman LC, Snyman LC. Prevention of cervical cancer - how long before we get it right? S Afr J Obstet Gynaecol 2013;19:2.

19 Snyman LC, Herbst U. Reasons why unscreened patients with cervical cancer present with advanced stage disease. South Afr J Gynaecol Oncol 2013;5:16-20.

20 Lind $\mathrm{H}$, Waldenström A-C, Dunberger G, et al. Late symptoms in long-term gynaecological cancer survivors after radiation therapy: a population-based cohort study. Br J Cancer 2011;105:737-45.

21 Andersen BL, Woods X, Cyranowski J. Sexual self-schema as a possible predictor of sexual problems following cancer treatment. Can J Human Sexual 1994;3.

22 Woods NF, Woods NF. Toward a holistic perspective of human sexuality: alterations in sexual health and nursing diagnoses. Holist Nurs Pract 1987;1:1-11.

23 Cleary V, Hegarty J. Understanding sexuality in women with gynaecological cancer. Eur J Oncol Nurs 2011;15:38-45.

24 Gilbert E, Ussher JM, Perz J. Sexuality after gynaecological cancer: a review of the material, intrapsychic, and discursive aspects of treatment on women's sexual-wellbeing. Maturitas 2011;70:42-57.

25 Thorne S. Interpretive description: qualitative research for applied practice. Routledge, 2016.

26 Thorne S, Kirkham SR, O'Flynn-Magee K. The analytic challenge in interpretive description. Int J Qual Methods 2004;3:1-11.

27 Sandelowski M, Barroso J. Classifying the findings in qualitative studies. Qual Health Res 2003;13:905-23.

28 Thorne S, Kirkham SR, MacDonald-Emes J. Interpretive description: a noncategorical qualitative alternative for developing nursing knowledge. Res Nurs Health 1997;20:169-77.

29 Giacomini M. Theory matters in qualitative health research The Sage handbook of qualitative methods in health research, 2010: 125-56.

30 Etikan I, Etikan I, Musa SA. Comparison of convenience sampling and purposive sampling. Am J Theor App/ Stats 2016;5:1-4

31 Miles MB, Huberman AM, Huberman MA, et al. Qualitative data analysis: an expanded sourcebook. sage, 1994.

32 Bayer AM, Cabrera LZ, Gilman RH, et al. Adolescents can know best: using concept mapping to identify factors and pathways driving adolescent sexuality in Lima, Peru. Soc Sci Med 2010;70:2085-95.

33 Harrison A, Xaba N, Kunene P, et al. Understanding young women's risk for HIV/AIDS: adolescent sexuality and vulnerability in rural KwaZulu/Natal. Society Trans 2001;32:69-78.

34 Trotter RT, Potter JM. Pile sorts, a cognitive anthropological model of drug and AIDS risks for Navajo teenagers: assessment of a new evaluation tool. Drugs Soc 1993;7:23-39.

35 Barton KC. Elicitation techniques: Getting people to talk about ideas they don't usually talk about. Theory Res Soc Educ 2015;43:179-205.

36 Ensign J, Gittelsohn J. Health and access to care: perspectives of homeless youth in Baltimore City, U.S.A. Soc Sci Med 1998:47:2087-99.

37 Yeh H-W, Gajewski BJ, Perdue DG, et al. Sorting it out: pile sorting as a mixed methodology for exploring barriers to cancer screening. Qual Quant 2014;48:2569-87.

38 Bourey C, Stephenson R, Bartel D, et al. Pile sorting innovations: exploring gender norms, power and equity in sub-Saharan Africa. Glob Public Health 2012;7:995-1008. 
39 Maitra S, Schensul SL. Reflecting diversity and complexity in marital sexual relationships in a low-income community in Mumbai. Cult Health Sex 2002;4:133-51.

40 Clarke V, Braun V, Hayfield N. Thematic analysis. In: Qualitative psychology: a practical guide to research methods, 2015: 222-48.

41 Tamale S. African sexualities: a reader: Fahamu/Pambazuka, 2011.

42 Gilbert E, Ussher JM, Perz J. Renegotiating sexuality and intimacy in the context of cancer: the experiences of carers. Arch Sex Behav 2010;39:998-1009.

43 Shefer T, Boonzaier F, Kiguwa P. The gender of psychology: Juta academic, 2006.

44 Hollway W, Hollway W. Women's power in heterosexual sex. Womens Stud Int Forum 1984;7:63-8.

45 Smith JEH. Embodiment [Internet]. Oxford University Press, 2016.

46 Stead ML, Fallowfield L, Selby P, et al. Psychosexual function and impact of gynaecological cancer. Best Pract Res Clin Obstet Gynaecol 2007;21:309-20.

47 Laganà L, McGarvey EL, Classen C, et al. Psychosexual dysfunction among gynecological cancer survivors. J Clin Psychol Med Settings 2001;8:73-84.

48 Andersen BL, Hacker NF. Treatment for gynecologic cancer: a review of the effects on female sexuality. Health Psychol 1983;2:203-21.

49 Gamel C, Hengeveld M, Davis B. Informational needs about the effects of gynaecological cancer on sexuality: a review of the literature. J Clin Nurs 2000;9:678-88.

50 Juraskova I, Butow P, Robertson R, et al. Post-treatment sexual adjustment following cervical and endometrial cancer: a qualitative insight. Psychooncology 2003;12:267-79.

51 Lamb MA, Sheldon TA. The sexual adaptation of women treated for endometrial cancer. Cancer Pract 1994;2:103-13.

52 Williams SJ, Williams SJ. The vicissitudes of embodiment across the chronic illness trajectory. Body Soc 1996;2:23-47.

53 Gilbert E, Ussher JM, Perz J. Embodying sexual subjectivity after cancer: a qualitative study of people with cancer and intimate partners. Psychol Health 2013;28:603-19.

54 Riechers EA, Riechers EA. Including partners into the diagnosis of prostate cancer: a review of the literature to provide a model of care. Urol Nurs 2004;24:22-9.

55 Maughan K, Heyman B, Matthews M. In the shadow of risk. How men cope with a partner's gynaecological cancer. Int J Nurs Stud 2002;39:27-34.

56 Harden J, Schafenacker A, Northouse L, et al. Couples' experiences with prostate cancer: focus group research. Oncol Nurs Forum 2002;29:701-9.

57 Sanders S, Pedro LW, Bantum Erin O'Carroll, et al. Couples surviving prostate cancer: long-term intimacy needs and concerns following treatment. Clin J Oncol Nurs 2006;10:503-8.

58 Greimel ER, Winter R, Kapp KS, et al. Quality of life and sexual functioning after cervical cancer treatment: a long-term follow-up study. Psychooncology 2009;18:476-82.

59 Schultz WCMW, van De Wiel HBM, Bouma J, et al. Gynaecological conditions and sexual dysfunction. Sex Marital Ther 1991;6:177-94.

60 Van De Wiel HBM, Schultz WCMW, Wouda J, et al. Sexual functioning of partners of gynaecological oncology patients: a pilot study on involvement, support, sexuality and relationship. Sex Marital Ther 1990;5:123-30.

61 Maree JE, Mosalo A, Wright SCD. 'It depends on how the relationship was before you became ill': Black South African women's experiences of life partner support through the trajectory of cervical cancer. Eur J Cancer Care 2013;22:459-67.

62 Becker M, Malafy T, Bossart M, et al. Quality of life and sexual functioning in endometrial cancer survivors. Gynecol Oncol 2011:121:169-73.

63 Nout RA, van de Poll-Franse LV, Lybeert MLM, et al. Long-term outcome and quality of life of patients with endometrial carcinoma treated with or without pelvic radiotherapy in the post operative radiation therapy in endometrial carcinoma 1 (PORTEC-1) trial. J Clin Oncol 2011;29:1692-700.

64 Onujiogu N, Johnson T, Seo S, et al. Survivors of endometrial cancer: who is at risk for sexual dysfunction? Gynecol Oncol 2011;123:356-9.

65 Sekse RJT, Hufthammer KO, Vika ME. Sexual activity and functioning in women treated for gynaecological cancers. J Clin Nurs 2017;26:400-10.

66 Ditto A, Martinelli F, Borreani C, et al. Quality of life and sexual, bladder, and intestinal dysfunctions after class III nerve-sparing and class II radical hysterectomies: a questionnaire-based study. Int $J$ Gynecol Cancer 2009;19:953-7.
67 Korfage IJ, Essink-Bot M-L, Mols F, et al. Health-related quality of life in cervical cancer survivors: a population-based survey. Int J Radiat Oncol Biol Phys 2009;73:1501-9.

68 Donovan KA, Taliaferro LA, Alvarez EM, et al. Sexual health in women treated for cervical cancer: characteristics and correlates. Gynecol Oncol 2007;104:428-34.

69 Rowlands IJ, Lee C, Beesley VL, et al. Predictors of sexual wellbeing after endometrial cancer: results of a national self-report survey. Support Care Cancer 2014;22:2715-23.

70 Hyde A. The politics of heterosexuality--a missing discourse in cancer nursing literature on sexuality: a discussion paper. Int $J$ Nurs Stud 2007;44:315-25.

71 Parton C, Ussher JM, Perz J. Experiencing menopause in the context of cancer: women's constructions of gendered subjectivities. Psychol Health 2017;32:1109-26.

72 Ussher JM, Perz J, Gilbert E, et al. Renegotiating sex and intimacy after cancer: resisting the Coital imperative. Cancer Nurs 2013;36:454-62.

73 Ussher JM, Perz J, Gilbert E. Women's sexuality after cancer: a qualitative analysis of sexual changes and Renegotiation. Women Ther 2014;37:205-21.

74 Potts A. The science/fiction of sex: feminist deconstruction and the vocabularies of heterosex. Psychology Press, 2002.

75 Tiefer L. The medicalization of sexuality: conceptual, normative, and professional issues. Annual Rev Sex Res 1996;7:252-82.

76 Tiefer L. The selling of 'female sexual dysfunction'. J Sex Marital Ther 2001;27:625-8.

77 Coker AL, Sanderson M, Fadden MK, et al. Intimate partner violence and cervical neoplasia. J Womens Health Gend Based Med 2000;9:1015-23.

78 Coker AL, Hopenhayn C, DeSimone CP, et al. Violence against women raises risk of cervical cancer. $J$ Womens Health 2009;18:1179-85.

79 Bergmark K, Åvall-Lundqvist E, Dickman PW, et al. Synergy between sexual abuse and cervical cancer in causing sexua dysfunction. J Sex Marital Ther 2005;31:361-83.

80 Service SAP. Crime situation in Republic of South Africa twelve (12) months (April to March 2018_19). South Africa: Department of Police, 2019.

81 Rasmusson E-M, Thomé B. Women's Wishes and Need for Knowledge Concerning Sexuality and Relationships in Connection with Gynecological Cancer Disease. Sex Disabil 2008;26:207-18.

82 Herbenick D, Reece M, Hollub A, et al. Young female breast cancer survivors: their sexual function and interest in sexual enhancement products and services. Cancer Nurs 2008;31:417-25.

83 Rees CE, Bath PA, Lloyd-Williams M. The information concerns of spouses of women with breast cancer: patients' and spouses' perspectives. J Adv Nurs 1998;28:1249-58.

84 Archibald S, Lemieux S, Byers ES, et al. Chemically-induced menopause and the sexual functioning of breast cancer survivors. Women Ther 2006;29:83-106.

85 Liao LM. Learning to assist women born with atypical genitalia: journey through ignorance, taboo and dilemma. J Reprod Infant Psychol 2003;21:229-38.

86 Schwartz S, Plawecki HM. Consequences of chemotherapy on the sexuality of patients with lung cancer. Clin $J$ Oncol Nurs 2002;6:212-6.

87 Almont T, Farsi F, Krakowski I, et al. Sexual health in cancer: the results of a survey exploring practices, attitudes, knowledge, communication, and professional interactions in oncology healthcare providers. Support Care Cancer 2019;27:887-94

88 Chow KM, H Chan CW, Chan JCY. Effects of psychoeducational interventions on sexual functioning, quality of life and psychological outcomes in patients with gynaecological cancer: a systematic review. JBI Libr Syst Rev 2012;10:4077-164.

89 Cleary V, McCarthy G, Hegarty J. Development of an educational intervention focused on sexuality for women with gynecological cancer. J Psychosoc Oncol 2012;30:535-55.

90 Sekse RJT, Blaaka G, Buestad I, et al. Education and counselling group intervention for women treated for gynaecological cancer: does it help? Scand J Caring Sci 2014;28:112-21.

91 Pistrang N, Jay Z, Gessler S, et al. Telephone peer support for women with gynaecological cancer: recipients' perspectives. Psychooncology 2012;21:1082-90.

92 Huntingdon B, Schofield P, Wolfowicz Z, et al. Toward structured peer support interventions in oncology: a qualitative insight into the experiences of gynaecological cancer survivors providing peer support. Support Care Cancer 2016;24:849-56.

93 Bonner C, Nattress K, Anderson C, et al. Chore or priority? Barriers and facilitators affecting dilator use after pelvic radiotherapy for gynaecological cancer. Support Care Cancer 2012;20:2305-13. 
94 Punt L. Patient compliance with the use of vaginal Dilators following pelvic radiotherapy for a gynaecological cancer. J Radiother Pract 2011;10:13-25.

95 Seibaek L, Petersen LK. Nurse-Led rehabilitation after gynaecological cancer surgery. Supportive Care in Cancer 2009;17:601-5.

96 Cook O, Mclntyre M, Recoche K. Exploration of the role of specialist nurses in the care of women with gynaecological cancer: a systematic review. J Clin Nurs 2015;24:683-95.

97 Parkinson N, Pratt H. Clinical nurse specialists and the psychosexual needs of patients with gynaecological cancer. J Br Menopause Soc 2005;11:33-5.

98 Maughan $\mathrm{K}$, Clarke $\mathrm{C}$. The effect of a clinical nurse specialist in gynaecological oncology on quality of life and sexuality. J Clin Nurs 2001;10:221-9.
99 Olesen ML, Hansson H, Ottesen B, et al. The psychosocial needs of gynaecological cancer survivors: a framework for the development of a complex intervention. Eur J Oncol Nurs 2015;19:349-58.

100 Schover LR, Yuan Y, Fellman BM, et al. Efficacy trial of an Internetbased intervention for cancer-related female sexual dysfunction. J Natl Compr Canc Netw 2013;11:1389-97.

101 Hersch J, Juraskova I, Price M, et al. Psychosocial interventions and quality of life in gynaecological cancer patients: a systematic review. Psychooncology 2009;18:795-810.

102 Teo I, Krishnan A, Lee GL. Psychosocial interventions for advanced cancer patients: a systematic review. Psychooncology 2019;28:1394-407. 